\title{
DEVELOPING A CONCEPTUAL FRAMEWORK FOR IMPLEMENTING E-GOV PROJECT [DEVELOPING COUNTRIES]
}

\author{
Mohamed Al Kilani and Volodymyr Kobziev \\ Kharkov National University of Radio Electronics, Kharkov, Ukraine
}

\begin{abstract}
Successful implementation of e-government services requires identifying all the main factors and elements that contribute directly towards providing the electronic services, as well as a clear vision of their benefits. This paper aims to develop a conceptual framework for e-government implementation in developing countries and give a comprehensive picture of the main factors of the e-government project, clarifying the main elements of each factor.
\end{abstract}

\section{KEYWORDS}

E-government, Technology Factor, Organizational Factor, Environmental Factor, Developing Countries

\section{INTRODUCTION}

Many developing countries such as India and Trinidad are not aware of the importance of e-government in improved data gathering and record, as well as increased interaction between the government and its citizen (Donnell, Boyle, and Timonen, 2003; Manoharan and McQuiston, 2018). Successful implementation of e-government project requires identifying the important factors such as Technology Factors, Organization Factors, and Environmental Factors (Pudjianto and Hangjung, 2009).

This paper aims to develop a conceptual framework for an e-government project and give a comprehensive picture of the main factors that affect its implementation in developing countries.

\section{WHAT IS E-GOVERNMENT}

E-government has become a key element in the organization of administrative structure that provides communication channels between the government institutions and contributes to improving electronic services to the public (Dada, 2006; Ziemba, Zelazny, and Papaj, 2013). Alshehri and Drew (2010) defined the e-government as a way of providing service through the web-based portal and empowering the beneficiaries to access their information anywhere at any time. Moreover, Drigas and Koukianakis (2009) noted that the e-government is a channel to increase the transparency and the interaction with citizens.

\section{E-GOVERNMENT ADOPTION FRAMEWORK}

This section identifies the conceptual framework and the main factors that influences the implementation of e-government. The framework addresses the shortcoming of existing models by identifying factors that affect e-government project implementation in developing countries.

\subsection{Environmental Factors}

The environmental factors can impact the successful adoption of an e-government project in the developing country. The environmental factor refer to suitable environments in which an organization can apply 
e-services. The environmental factors in developing countries that can affect the adoption of e-government project include economic environment, political environment, legal environment, and the digital divide.

The economic factor in the e-government project is considered as the engine to support and develop the e-government and e-projects such as e-commerce as well as e-business (Mistry and Jalal, 2012). Addressing the political legal issue is a very important stage in an e-government project implementation. In order to implement an e-government project, a comprehensive assessment of local laws must be made, and then implement the project according as per the legal framework that will meet the needs of all beneficiaries (Alrawabdeh, 2014). The digital divide is the difference between those who use the technology smoothly and those who have difficulty in using digital technology. The reason of this gap may be fear of using digital technology, low educational level, poverty or age (Dada, 2006).

\subsection{Organization Factors}

The organizational factors include organizational culture, organization size, human recourses, change management, and top management support. The proponents of an e-government project emphasized the importance of organizational issues and described it as the main unit for introduction of e-government initiatives (Alshehri and Drew, 2010; Omari, 2013).

There is an inverse relationship between organizational culture and use of information technology that could have an essential and effective impact on e-government performance (Dasgupta and Gupta, 2010) . During the adoptation of an e-government project, it will be necessary to change the mentality of the top managers and employees, as well as beneficiaries of e-government services. The organization size in the adoption of e-government project has an effect on efficiency and development performance.

The organization size has been considered as a major variable in the process of adopting e-government services (Rehman, Fatima, and Imran, 2009; Vahtera, 2008). Human resource is one of the main factors in the e-government project. Adoption of e-government is an effort to restructure the existing system and build a structure that contains a transparent, accountable, efficient, and the effective system.

\subsection{Technology Factors}

Information and communication technology infrastructure is the main factor of the e-government project, and one of the challenges faced by the e-government. ICT infrastructure is the main factor for reducing the digital divide between rural and urban areas. ICT infrastructure includes the main components of the technology factor such as software, hardware, telecommunication, internet, and database management systems (Alghamdi, Goodwin, and Rampersad, 2014; Nkohkwo and Islam, 2013).

ICT tools refer to components required to implement an e-Government project. The components include hardware, software, web servers, application servers, PCs, printers, scanners, routers, switches, firewalls, data, and application development tools.

The successful adoption of the e-government depends on the security and privacy of information. Security and Privacy contribute significantly to increasing the trust between the e-government's departments and the beneficiaries (AbuAli and Almarabeh, 2010). In the e-government services, the security and privacy section is considered as a critical factor in ensuring information and data privacy and protection (Alshehri and Drew, 2010).

\section{PRIORITY IN THE IMPLEMENTATION STAGES}

The main goal of developing a conceptual framework of an e-government project is to clarify the key factors and critical elements needed in developing a countries environment to implement an e-government project successfully. The conceptual framework includes all the factors and elements that are required for better understanding and identification of the barriers, challenges, and benefits influencing the implementation of the e-government project in developing countries.

Table 1, Figure 1 and Figure 2 illustrates the steps and priority for implementation of an e-government project in developing countries. 
Table 1. Stages for E-government Implementation

\begin{tabular}{|c|c|}
\hline STAGES & REFERENCES \\
\hline 1. Readiness to Change & \multirow{7}{*}{$\begin{array}{l}\text { Heeks, 2003; Ndou, 2004; Wimmer, Codagnone, and } \\
\text { Janssen, 2008; Geri 2009; Pudjianto and Hangjung, } 2009 \text {; } \\
\text { Rabaiah and Vandijck, 2009; Wang, Lee, and Lim, } 2009 .\end{array}$} \\
\hline 2. Supporting the Process of Change & \\
\hline 3. Provide Roadmap to Move to E-government & \\
\hline $\begin{array}{l}\text { 4. The Involvement of the Private Sector in the Process } \\
\text { of Change }\end{array}$ & \\
\hline 5. Resistance to Change & \\
\hline 6. Gain the Beneficiaries Trust & \\
\hline 7. Evaluate Performance and Improvement & \\
\hline
\end{tabular}

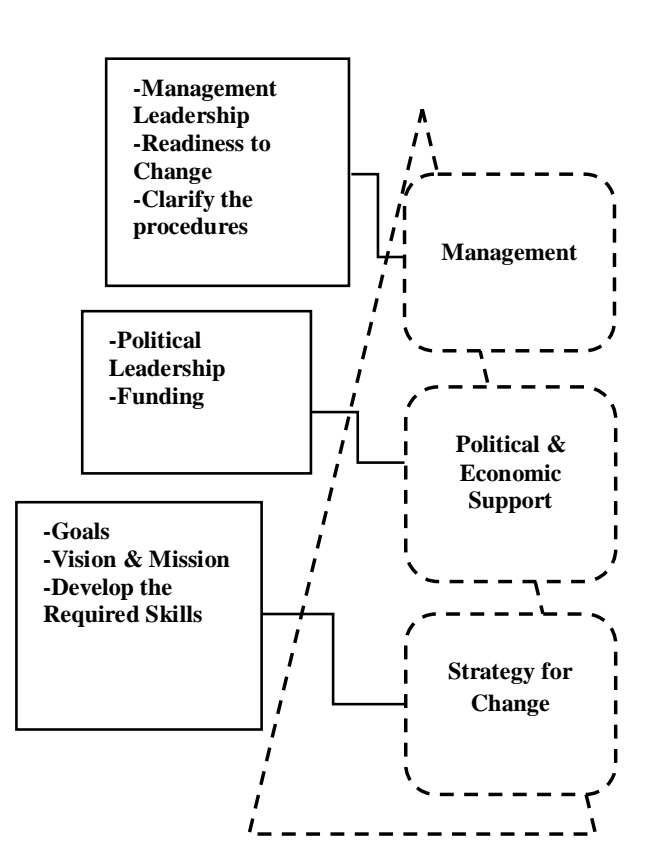

Figure 1. Priority of Stages for E- government Implementation

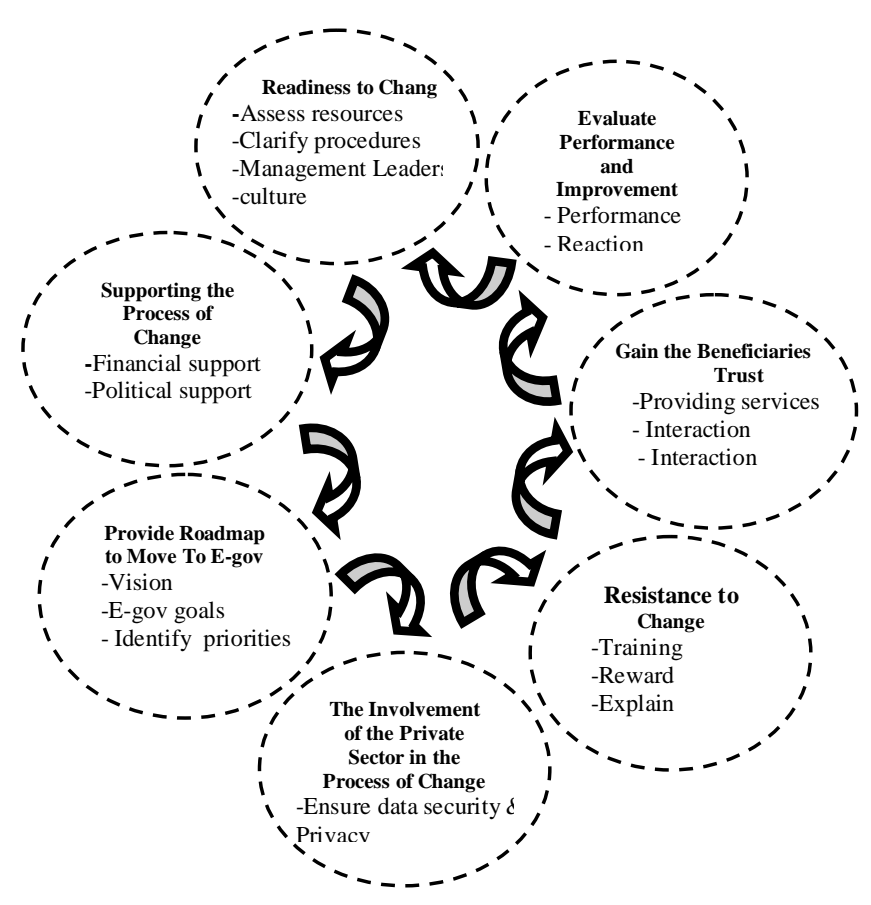

Figure 2. Stages for E-government Implementation

\section{CONCLUSION, IMPLICATIONS, AND SCOPE FOR FUTURE STUDY}

The paper provides a clear vision for implementation of an e-government project in developing countries. The paper clarifies the conceptual framework for adopting the e-government project including all the main factors (technology, organization, environment) of the e-government project. The factors are complementary to each other, each of which has a key role in the success of an e-government project.

The requirements of adopting an e-government project were explained and all factors that affect implementation of the project were assessed. Moreover, the paper has identified the priorities that can influence the implementation of an e-government project. The research work can have implications in government policies developed for e-government implement in developing countries.

The research work contributes to the knowledge regarding factors affecting implementation of an e-government project in developing countries. Further research study can be carried out to find out cost of implementing the project in different countries. 


\section{REFERENCES}

AbuAli, A. and Almarabeh, T., 2010. A General Framework for E-Government: Definition Maturity Challenges , Opportunities , and Success. European Journal of Scientific Research, 39, pp. $29-42$.

Alghamdi, Ibrahim A., Goodwin, R., and Rampersad, G., 2014. Organizational E-Government Readiness: An Investigation in Saudi Arabia. International Journal of Business and Management, Vol. 9, pp. 14-24.

Alrawabdeh, Wasfi, 2014. The Impact of Environmental Factors on E-Government Implementation: The Case of Jordan Author Detail: Wasfi Alrawabdeh- Faculty of Economics and Management Science, Hashemite University, Jordan. International Journal of Management Sciences and Business Research, Vol. 3, pp. 1-7.

Alshehri, Mohammed Abdulrahman and Drew, Steve, 2010. Implementation of E-Government: Advantages and Challenges. Proceedings of the International Conference E-Activity and Leading Technologies 2010, Oviedo, Spain, pp. 79-86.

Dada, Danish, 2006. The Failure of E-Government in Developing Countries: A Literature Review. The Electronic Journal on Information Systems in Developing Countries, EJISDC, Vol. 7, pp. 1-10.

Donnell, Orla O, Boyle, R. and Timonen, Virpi, 2003. Transformational Aspects of E-Government in Ireland : Issues to Be Addressed. Electronic Journal of e-Government, Vol. 1, pp. 22-30.

Drigas, Athanasios, and Koukianakis, Leyteris, 2009. Government Online: An E-Government Platform to Improve Public Administration Operations and Services. Springer-Verlag, Berlin, Germany.

Fuchs, Christian and Horak, Eva, 2008. Africa and the Digital Divide. Telematics and Informatics, Vol. 25, pp. $99-116$.

Heeks, R., 2003. Most eGovernment Development Projects Fail. Institute for Development Policy and Management.

Krishnan, Satish, and Teo, T. H. T., 2010. E-Government, E-Business, and National Environmental Performance. Proceedings of the Pacific Asia Conference on Information Systems. Brisbane, Australia, pp. 7-11.

Manoharan, Aroon P., and McQuiston, James, 2018. Innovative Perspectives on Public Administration in the Digital Age. IGI Global, Pennsylvania, USA.

Mistry, Jamshed J. and Jalal, Abu, 2012. An Empirical Analysis of the Relationship between E-Government and Corruption, International Journal of Digital Accounting Research, Vol. 12, pp. 145-76.

Ndou, V., 2004. E- Government for Developing Countries: Opportunities and Challenges. The Electronic Journal on Information Systems in Developing Countries, Vol. 18, pp. 1-24.

Nkohkwo, Quinta Nven-akeng and Sirajul Islam, M., 2013. Challenges to the Successful Implementation of E-Government Initiatives in Sub-Saharan Africa : A Literature Review Research Methodology. Electronic Journal of e-Government, Vol. 11, pp. 253-267.

Omari, Asem, 2013. Technology Adoption in the Arabian Gulf Countries. International Journal of Computer Science, Engineering and Information Technology (IJCSEIT), Vol. 3, pp. 1-8.

Pudjianto, Boni Wahyu, and Hangjung, Zo, 2009. Factors Affecting E-Government Assimilation in Developing Countries. SSRN Electronic Journal, pp. 1-14.

Rabaiah, A. and Vandijck, E., 2009. 'A Strategic Framework of E-Government: Generic and Best Practice', Electronic Journal of e-Government, 7, pp. 241-258.

Rehman, A., Fatima, A., and Imran, R., 2009. Transformational Leadership and Organizational Innovation: Moderated by Organizational Size. African Journal of Business Management, Vol, 3, pp. 678-684.

Sharma, Gajendra, Bao, Xi, and Peng, Li, 2014. Public Participation and Ethical Issues on E-Governance: A Study Perspective in Nepal, Electronic Journal of e-Government, Vol. 12, pp. 82-96.

Subhasish Dasgupta and Babita Gupta, 'Organizational Culture and Technology Use in a Developing Country: An Empirical Study', Proceedings of SIG GlobDev 3rd Annual Workshop, St. Loius, USA, 2010.

Vahtera, Annukka Maria, 2008. Organisational Factors Affecting IT Innovation Adoption in the Finnish Early Childhood Education. Proceedings of the 16th European Conference on Information Systems, Galway, Ireland, pp. 1106-1116.

Wang, Mo, Lee, One-Ki, and Lim, K.H., 2009. Knowledge Management Systems Diffusion in Chinese Enterprises: A Multi-Stage Approach with the Technology-Organization-Environment Framework. Journal of Global Information Management (JGIM), Vol. 17, pp. 70-84.

Wimmer, Maria, Codagnone, Cristiano, and Janssen, Marijn, 2008. Future E-Government Research: 13 Research Themes Identified in the eGovRTD2020 Project. Proceedings of the 41st Annual Hawaii International Conference on System Sciences (HICSS 2008), Waikoloa, USA, pp. 223-223.

Żelazny, Rafał, Ziemba, Ewa, and Tomasz Papaj, 2013. A Model of Success Factors for E-Government Adoption. Issues in Information Systems, Vol. 14, pp. 87-100.

Zhao, Fang, Shen, Kathy Ning and Collier, Alan, 2014. Effects of National Culture on E-Government diffusion - A Global Study of 55 Countries. Information \& Management, Vol. 51, pp. 1005-16. 